\title{
Process Parameter Correlation in Low Pressure Hydro Forming of 6063-O Aluminium Tubes
}

\author{
J. SAJI SOUNDARA RAJ*, T. CHRISTOPHER**, K. KALAICHELVAN*** \\ *Department of Aeronautical Engineering, Noorul Islam University, Kumara coil, India, \\ E-mail: sajisoundararajph.d2018@gmail.com \\ **Department of Mechatronics Engineering, Kamaraj college of Engineering and Technology, Madurai, India \\ ***Department of Ceramic Technology, Anna University, Chennai 600025, India \\ crossref http://dx.doi.org/10.5755/j01.mech.25.1.20326
}

\section{Introduction}

The low-pressure hydro-forming process gets great attention in recent years among various automotive and aerospace industries. It is carried out with constant internal pressure and axial force to form the components. Fig. 1 shows the sectional view of hydro-forming set up that consists of three major components. It has a forming die, punch and tube to be formed. The forming die should be designed according to the final shape of component. The quality of final product depends on various parameters and some of the important parameters are tube wall thickness, tube length, loading time and coefficient of friction. These parameters are unique when different tube component is fabricated using this process and these factors should be considered within an optimum range during fabrication. However, for a constant die arrangement, the outer diameter of tube remains constant and other factors namely wall thickness, tube length, internal pressure and axial force can be varied. All these variation affects the wall thinning / thickening and protrusion profile.

Many researchers have been carried out to understand these complex phenomena as it undergoes severe plastic deformations. Alaswad et al [1] reviewed the tube hydro forming process and related research. The article elaborates various analytical solutions, numerical simulation methods and experimentations involved in the hydro forming process. Zhan et al. [2] reviewed the plastic forming of thin walled welded tubes using various forming methods. The difficulties to handle the effect of weld joint heterogeneity, residual stress and distortion of welded components in the forming process are yet to be explored. Liu et al. [3] developed an analytical model to calculate the critical stress that produces the side wall and corner wrinkling on $\mathrm{T}$-joint thin walled hydro forming tubular components. The effect of stress ratio, tube diameter to thickness ratio and material property constant on wrinkling phenomena were studied. It was reported that the wrinkling can be avoided if the pressure increased beyond the critical stress.

Lang et al. [4] developed forming limit diagram considering through thickness stress and temperature using $\mathrm{M}-\mathrm{K}$ theory. The constitutive model was developed for 5A06 aluminium alloy including temperature and through thickness normal stress. Cui et al. [5] investigated the effect of normal stress in thickness direction during hydro bulging of $5 \mathrm{~A} 02$ aluminium tubes. It was inferred that the normal stress along thickness has negligible influence on the plastic deformation till necking and it only influence fracture be- haviour of material. Khalfallah et al. [6] developed constitutive material constant of tubular materials and validated the developed model using experiments. The biaxial state of stress induced in the component during hydro forming is one of the major factors that limit the formability of tubular components. The behaviour of such components was investigated using developed model. Iorio et al. [7] investigated the applicability of local intermediate heat treatment of 6061 aluminium tube that are fabricated by tubular hydro forming. It was suggested that the local heat treatment reduces process time compared to the conventional annealing process. He et al. [8] proposed an analytical solution to measure the induced stress in hydro bulging of tubes. The bulge height and pole thickness for varying internal pressure was analyzed. The developed model was checked for various constrain conditions and validated by experiments. He et al. [9] presented a linear analytical model for predicting pole thickness during hydro bulging process. This model was proposed to predict the varying pole thickness and validated using experiments.

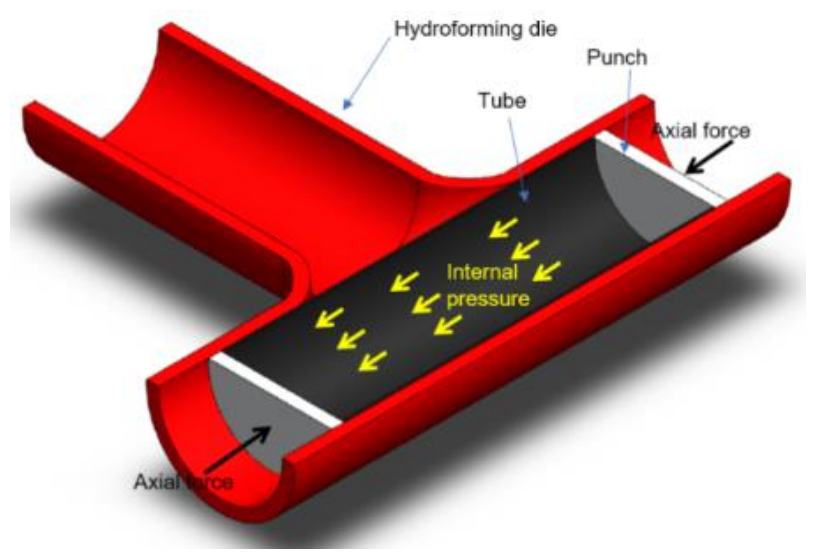

Fig. 1 Typical hydro-forming set-up

Park et al. [10] proposed an advanced sealing system for the hydro forming process to control the fluid leakage. It provides even stress distribution between tube and punch and arrest the leakage that improves the forming process. Nakamori et al. [11] investigated the dimensional accuracy of y-shaped tube hydro forming process on 6063-T5 using fuzzy controlled sensor system. The developed contact sensor and process improved the geometrical shape of the protrusion within $\pm 1 \mathrm{~mm}$ accuracy. Dong et al. [12] explained the limitations in high strength aluminium alloy forming process at room temperature. The forming of 6061 was investigated at elevated temperature by high pressure tubular forming process. It was inferred that the ageing of 
material during heat treatment and forming at elevated temperature improves the formability up to $25 \%$ by increasing the ductility of material. Yuan et al. [13] investigated wrinkling effects during hydro forming process adapting combined internal and external pressure situation. The experiments conducted using 5A02 thin walled aluminium alloy tubes for various pressure conditions. It was reported that the wrinkling formation highly depends on internal pressure and independent of external pressure.

Guo et al. [14] measured the ductile fracture criteria and developed constitutive equation for 6061-O alloy based on M-K theory in tube free bulging process. The numerical simulations were implemented using DEFORM-3D and compared with experimentally damaged components. Khodko et al. [15] demonstrated the free bulging of aluminium tube blank using numerical simulation and experiments. The simulations were carried out using LS-DYNA software to predict the internal pressure change during hydro forming process. The wave like phenomena of internal fluid originated from the displacement of lower and upper punch induced wavy profiles on the strain measurements.

Hashemi et al. [16] carried out numerical simulations to predict the ductile fracture of AA6063 aluminium tubes during free bulging. The analysis was carried out at elevated temperature and appropriate tensile test were also carried out to measure the fracture criterion based on temperature and strain rate. Cui et al. [17] investigated the double side tube hydro forming of tube in the square cross section. Numerical analysis was carried out to predict the critical strain in the transition region and validated by experiments. It was inferred that the external pressure improves the deformation of transition zone.

Zribi et al. [18] carried out inverse approach to identify the flow stress parameters of tubes during free bulging. Numerical analysis and experimental test results were utilized to optimize the constitutive constants. Bihamta et al. [19] investigated a new die design for tube hydro forming of complex tubular parts. During this process, the tubes were pre-formed before hydro forming. Also, it involved significant application of numerical simulations to develop the die design using Holloman's strain hardening relation. Alaswad et al. [20] carried out numerical simulations of single and bi-layer tube hydro forming and validated by experiments. It was intended to compare these two approaches using numerical simulations. Bulge height, wall thinning, and wrinkling were discussed for various load paths.

Zhang et al. [21] investigated hydro-mechanical deep drawing process using 6061-O material and inferred that the punch structure, internal pressure and die corner radius are influencing process parameters. The forming was successful when these parameters are optimized. Nikhare et al. [22] developed an analytical model to calculate internal pressure required in the low-pressure hydro forming process. It was stated that the yield stress of the material, tube thickness and length of tube in contact with die are highly influencing factors that determines the required internal pressure. Palumbo et al. [23] carried out research on warm hydro forming process on hard enable aluminium alloy material. The parameters that affect the hardening properties of material namely working temperature and exposure time were optimized to achieve final products.

It is noticed from the literature that many research has been carried out in the field of high pressure hydro forming process to optimize the process parameters with respect to geometrical conditions, namely, protrusion height and wall thickness. The optimized parameters reported in the literature are applicable to specific material and die designs. Some researcher, proposed analytical solutions to calculate maximum wall thinning, bulge shapes and induced stress. It is also noticed that finite element based numerical analysis are more often used to investigate this process as the tubular components required more analysis to understand its behaviour for various input conditions and validated by experiments.

However, very limited research on low pressure hydro forming process was reported in available literature. As, the correlations of various input parameters for the lowpressure hydro forming process varies with respect to die design, it is intended to develop a correlation of various input and output parameters of low pressure hydro forming process using customized die configurations. In the present work, correlation of input parameters namely, tube wall thickness, tube length, loading time and coefficient of friction are correlated with protrusion height and percentage change in wall thickness. The mathematical correlations are developed employing design of experiment approach that uses results from finite element analysis. The credibility of numerical model is validated using the data available in literature and further investigations are carried out using numerical analysis.

\section{Research strategy}

A systematic work flow is given in Fig. 2, that gives an overview of the methodologies implemented in this study

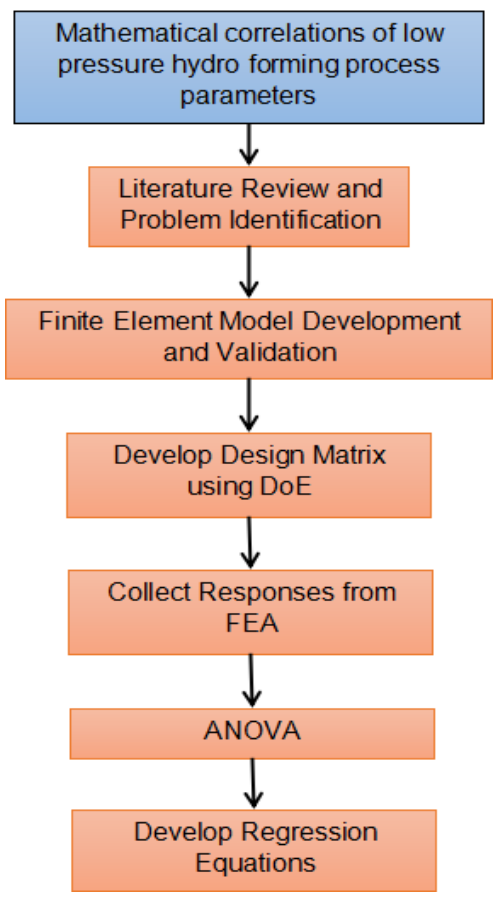

Fig. 2 Work flow

Critical process parameters are chosen based on literature and a design matrix is developed employing BoxBehnken design of experiment approach. Dynamic numerical investigations are performed by finite element analysis (FEA) using Abaqus-Explicit code for various combinations of process parameters. The credibility of developed dy- 
namic hydro-forming numerical model is validated with literature. The results are obtained from this investigation and significant parameters are identified using analysis of variance (ANOVA). Also, regression equations that relate the design parameters and responses are developed. The regression equations help to construct the response surfaces that graphically explain the correlation.

\section{Benchmark numerical analysis}

Numerical investigation based on finite element modelling is performed to estimate the characteristics of tubular hydro-formed component. A T-joint is formed from straight tube that requires a T-branched die. The set up consists of a hydro-forming die and tube to be formed. Threedimensional dynamic numerical analysis is developed using Abaqus-Explicit, considering symmetry, one half of the die and tube are modelled. As it is focused on the behaviour of hydro-formed tubular component, only the tube is modelled as deformable component and the die is considered as rigid component.

A benchmark numerical simulation is carried out and the results are validated with literature Alaswad et al. [20]. A tube of $120 \mathrm{~mm}$ length, outer diameter of $24 \mathrm{~mm}$ and wall thickness of $1.3 \mathrm{~mm}$ is considered. The model is created as three-dimensional solid component to represent more realistic behaviour. The tube material follows elasticplastic behaviour as it undergoes sever deformation during forming. The plasticity behaviour is modelled that obeys Holloman's power law as given in Eq. (1).

$$
\sigma=K e^{n}
$$

where: $\sigma$ is true stress, $e$ is plastic strain, $K=425.7$, is strength coefficient and $n=0.2562$ is strain hardening exponent Alaswad et al. [20] . The deformable tube model is meshed with continuum solid elements (C3D8R). The model consists of 2800 solid elements that is chosen without compromising the accuracy of results. The contact between meshed models is defined using surface-to-surface contact with the friction coefficient of 0.15 . In this process, axial feed and internal pressure is assigned that follows a specified load path as shown in Fig. 3.

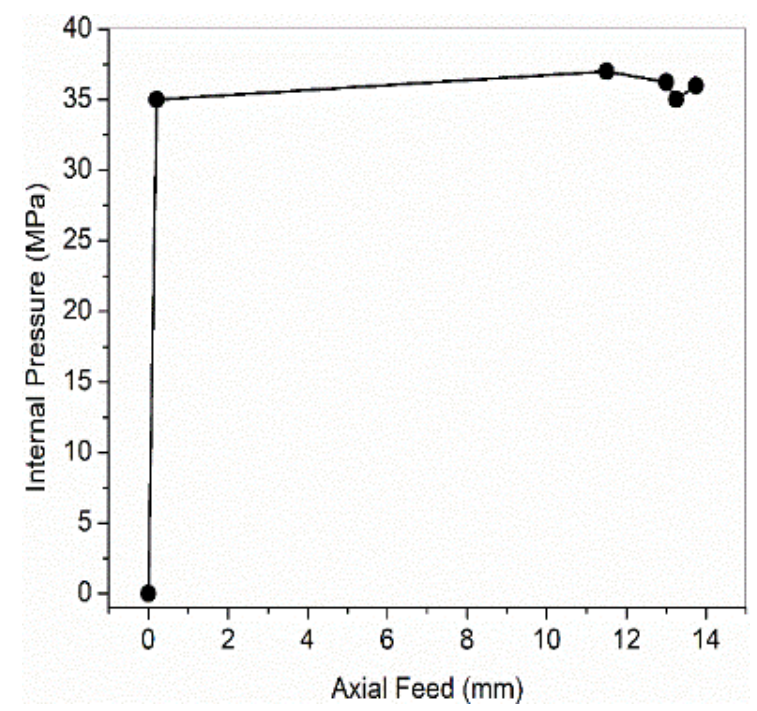

Fig. 3 Dynamic load path Alaswad et al. [20]

\section{Design of experiments approach}

In this study, the hydro-forming process of 6063-O tubes is carried out using a die as shown in Fig. 4.

The die is designed such that the outer diameter of tube to be formed is maintained as $12 \mathrm{~mm}$ and having a uniform diameter provision for protrusion profile. The geometry of tube is considered as one of the variables. The present study employs a constant die configuration and it is modelled as a rigid component. The hydro-forming process parameters are investigated using this specified die based on design of experiments approach employing Box-Behnken model.

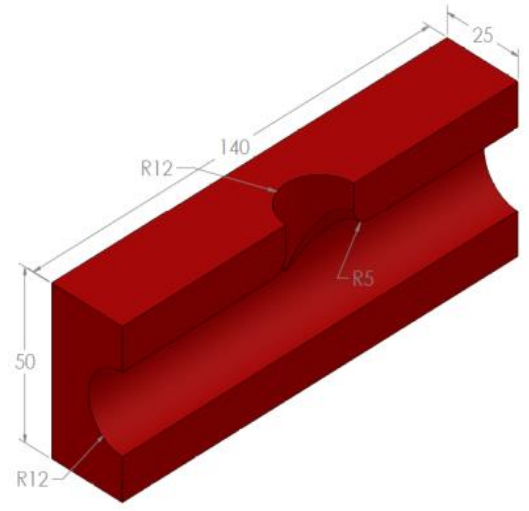

Fig. 4 Hydro-forming die (unit in $\mathrm{mm}$ )

\subsection{Box-Behnken Model}

A mathematical model is developed to correlate various input parameters, namely, tube wall thickness, tube length, coefficient of friction and loading time with protrusion height and change in wall thickness. This correlation is developed employing Box-Behnken approach as a quadratic polynomial equation. Box-Behnken model is a response surface design, specially made to require only 3 levels, coded as $-1,0$, and +1 . Table 1 , shows the range of input parameters considered for the tubular hydro-forming. It provides information about independent and dependent effects of input parameters on the specified responses.

Table 1

Hydro-forming parameters

\begin{tabular}{|l|c|c|c|}
\hline Range of Hydro-Forming Parameters & -1 & 0 & 1 \\
\hline Tube Wall Thickness, mm & 0.5 & 1 & 1.5 \\
\hline Tube Length, mm & 100 & 120 & 140 \\
\hline Loading Time, $\mathrm{s}$ & 2 & 4 & 6 \\
\hline Coefficient of Friction & 0.05 & 0.15 & 0.25 \\
\hline
\end{tabular}

A design matrix is developed based on the BoxBehnken model as shown in Table 2, that consists of various combinations of input within the given range. It consists of 29 combinations input that should be analysed and required responses are measured. As it is a face centred model it can be used to understand the process only within the given range. A linear regression method was used to fit the second order polynomial equation to the experimental data and identify the relevant model terms. The polynomial response model can be described as given in Eq. (2).

$$
y=\beta_{0}+\sum_{i=1}^{k} \beta_{i} x_{i}+\sum_{i=1}^{k} \beta_{i i} x_{i}^{2}+\sum_{i} \sum_{j} \beta_{i j} x_{i} x_{j}+e,
$$


where: $Y$ is the response; $x_{i}$ and $x_{j}$ are variables $(i, j$ ranges from 1 to $k) ; \beta_{0}$ is the model intercept coefficient; $\beta_{i, j}$ is interaction coefficients of linear terms; $k$ is the number of independent parameters $(k=4)$; and $e_{i}$ is the error. The model is started with a quadratic model and interaction terms and significant responses are found by analysis of variance (ANOVA). The significance of the factor is evaluated by the $F$-statistic that are calculated from the FEA data. The data are evaluated with various statistical analyses such as $p$ value, $F$ value, degrees of freedom (DF), sum of squares (SS), mean sum of squares (MSS), coefficient variation (CV), determination coefficient $R^{2}$, adjusted determination of the coefficient $R^{2} a$, etc. Based on the sum of squares obtained from the ANOVA, the percentage contributions for each individual factor are calculated. After fitting the data to the models, the generated data are used for plotting response surfaces and contour plots.

Table 2

Design matrix

\begin{tabular}{|c|c|c|c|c|}
\hline & Factor 1 & Factor 2 & Factor 3 & Factor 4 \\
\hline $\begin{array}{l}\text { S. } \\
\text { No }\end{array}$ & $\begin{array}{l}\text { A: tube wall } \\
\text { thickness }\end{array}$ & $\begin{array}{l}\text { B: tube } \\
\text { length }\end{array}$ & $\begin{array}{l}\text { C: load- } \\
\text { ing time }\end{array}$ & $\begin{array}{l}\text { D: coefficient of } \\
\text { friction }\end{array}$ \\
\hline & $\mathrm{mm}$ & $\mathrm{Mm}$ & $\mathrm{s}$ & - \\
\hline 1 & 1 & 100 & 4 & 0.05 \\
\hline 2 & 1 & 100 & 2 & 0.15 \\
\hline 3 & 0.5 & 120 & 4 & 0.25 \\
\hline 4 & 0.5 & 120 & 6 & 0.15 \\
\hline 5 & 0.5 & 140 & 4 & 0.15 \\
\hline 6 & 0.5 & 100 & 4 & 0.15 \\
\hline 7 & 1 & 140 & 2 & 0.15 \\
\hline 8 & 1 & 120 & 6 & 0.25 \\
\hline 9 & 1.5 & 120 & 2 & 0.15 \\
\hline 10 & 1 & 120 & 4 & 0.15 \\
\hline 11 & 1 & 140 & 4 & 0.05 \\
\hline 12 & 1 & 120 & 4 & 0.15 \\
\hline 13 & 1.5 & 120 & 4 & 0.05 \\
\hline 14 & 1 & 100 & 6 & 0.15 \\
\hline 15 & 1 & 140 & 4 & 0.25 \\
\hline 16 & 1 & 120 & 4 & 0.15 \\
\hline 17 & 1 & 140 & 6 & 0.15 \\
\hline 18 & 0.5 & 120 & 2 & 0.15 \\
\hline 19 & 1 & 120 & 4 & 0.15 \\
\hline 20 & 1.5 & 100 & 4 & 0.15 \\
\hline 21 & 0.5 & 120 & 4 & 0.05 \\
\hline 22 & 1 & 120 & 2 & 0.25 \\
\hline 23 & 1.5 & 120 & 4 & 0.25 \\
\hline 24 & 1 & 120 & 6 & 0.05 \\
\hline 25 & 1.5 & 120 & 6 & 0.15 \\
\hline 26 & 1 & 120 & 4 & 0.15 \\
\hline 27 & 1.5 & 140 & 4 & 0.15 \\
\hline 28 & 1 & 100 & 4 & 0.25 \\
\hline 29 & 1 & 120 & 2 & 0.05 \\
\hline
\end{tabular}

\section{Material model and boundary conditions}

The present research is carried out considering the elastic-plastic material behaviour as the tube to be formed undergoes severe plastic deformations. The tube is considered as 6063 aluminium alloy at annealed condition. The constant material properties used in this analysis is given in Table 3. To model the material behaviour more accurately, the classical Holloman's plasticity model is employed. The experimental stress-strain curve presented in the literature is referred and fitted to obtain the strength coefficient $K$ and strain hardening exponent $n$ for the tube material. Jain et al [24]. Based on these coefficients, the required flow curve is obtained and extrapolated to higher strain as shown in Fig. 5. The constitutive equation that defines the material flow curve is also noted in Fig. 5.

Table 3

Material properties of $6063-\mathrm{O}$

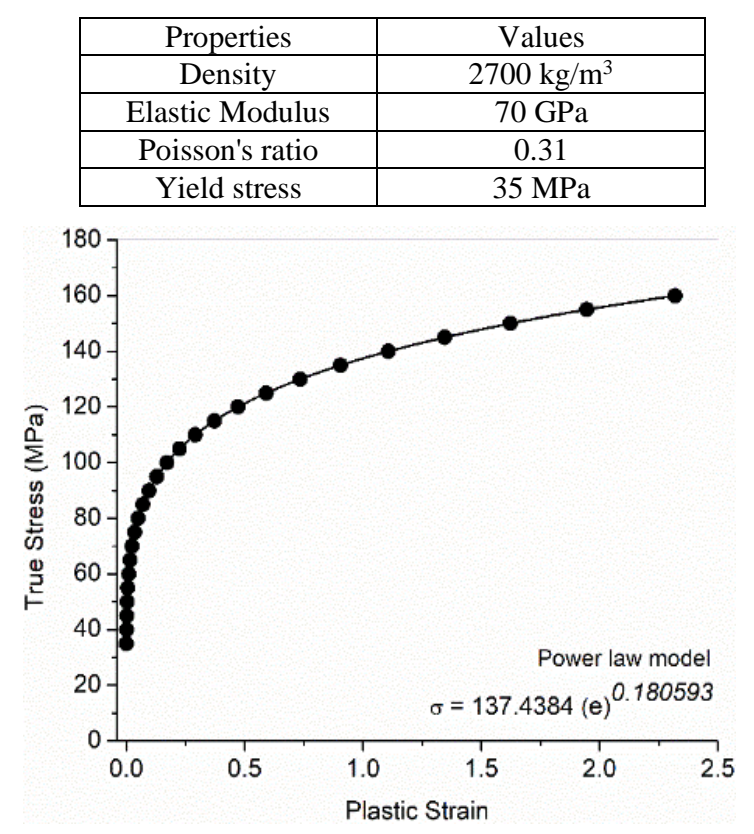

Fig. 5 6063-O flow curve

During forming two different loading conditions are involved, namely internal pressure and axial feed. In the developed model, the internal pressure required to onset the yield is calculated using Eq. (3). To find a suitable range of internal pressure for the specified range of tube configurations, $24 \mathrm{~mm}$ diameter and $4 \mathrm{~mm}$ tube wall thickness is chosen as a reference. Along with internal pressure, axial feed of $15 \mathrm{~mm}$ is applied on both the ends of tube for unit time during the process.

$$
P=\sigma_{y} \frac{2 t}{D_{o}-t},
$$

where: $P$ is internal pressure, $\mathrm{t}$ is tube wall thickness, $D_{0}$ is tube outer diameter and $\sigma_{y}$ is yield stress of material. The range of internal pressure is chosen with respect to the reference internal pressure of $4 \mathrm{MPa}$ at $1 \mathrm{~s}$. The lower and upper bound is chosen as $\pm 50 \%$ from the loading time while the internal pressure is kept constant as $4 \mathrm{MPa}$ for the analysis. The total time duration for the process is considered as variable while having constant amplitude of internal pressure and axial feed as shown in Figs. 6, a-c. The constant internal pressure is applied at various time period such that the rate of loading is altered during processing. Similarly, the axial feed of $15 \mathrm{~mm}$ is provided to the model to maintain a linear loading with respect to internal pressure. Such that the internal pressure and axial feeding is applied to maintain a linear loading path. It is noticed from the linear fit Fig. 6, c. of pressure and feed that the internal pressure of $0.26667 \mathrm{MPa}$ is increased for unit axial feed increment.

This internal pressure and axial feed loads are applied to the tube as shown in Fig. 7. A reference point, RP, 
at the centre of tube ends is created and it is assigned as a control point. The control point is coupled with the tube end surface to apply uniform loading. The dynamic load path of axial feed is directly assigned on the reference point that
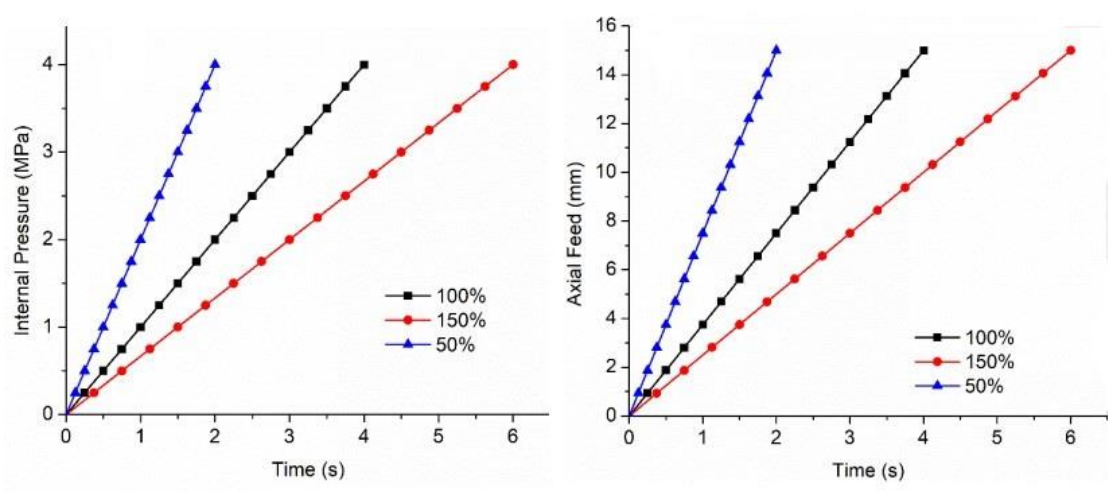

b

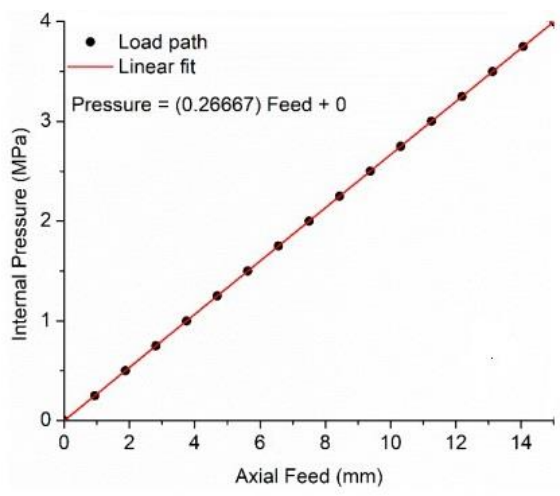

c

Fig. 6 Loading path, $\mathrm{a}$ - internal pressure; $\mathrm{b}$ - axial fee; $\mathrm{c}$ - linear loads

This internal pressure and axial feed loads are applied to the tube as shown in Fig. 7. A reference point, RP, at the centre of tube ends is created and it is assigned as a control point. The control point is coupled with the tube end surface to apply uniform loading. The dynamic load path of axial feed is directly assigned on the reference point that takes the uniformly distributed axial load during analysis. Also, the dynamic internal pressure is applied on the internal tube surface.

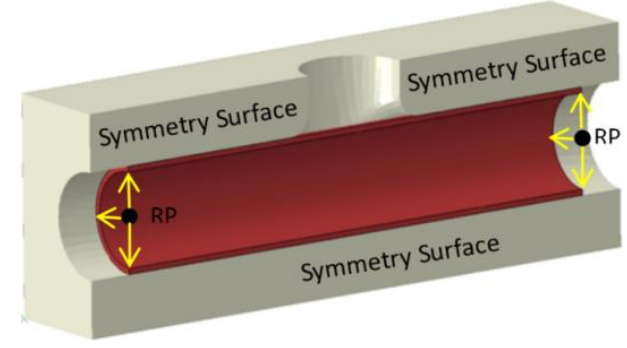

Fig. 7 Boundary conditions

As the model is developed as a symmetry component, the outer surface of die and tube are assigned symmetry constrained such that the component does not move through the symmetry surface. The hydro-forming die is takes the uniformly distributed axial load during analysis. Also, the dynamic internal pressure is applied on the internal tube surface.

fully constrained in the normal and transverse direction to the symmetry surface such that it does not move in space. A surface-to-surface contact constrain is also assigned to establish a contact between these two components such that the tube can be formed into the required die shape.

\section{Results and discussions}

\subsection{Benchmark validations}

The benchmark analysis is carried out to validate the developed numerical model with literature Alaswad et al. [20] . The deformed tube after loading is shown in Fig. 8, a, shows that it undergoes severe deformation through the T-branch and its length is significantly shortened. It is attributed to severe plastic strain induced at the junction of T-branch of inner and outer side of tube component as shown in Fig. 8, b. This higher plastic strain zone indicates the onset of necking in the component that leads to failure. However, the plastic strain distribution is not uniform throughout the tube component. Also, at the tube ends, slightly higher magnitude of plastic strain is observed due to axial feeding.

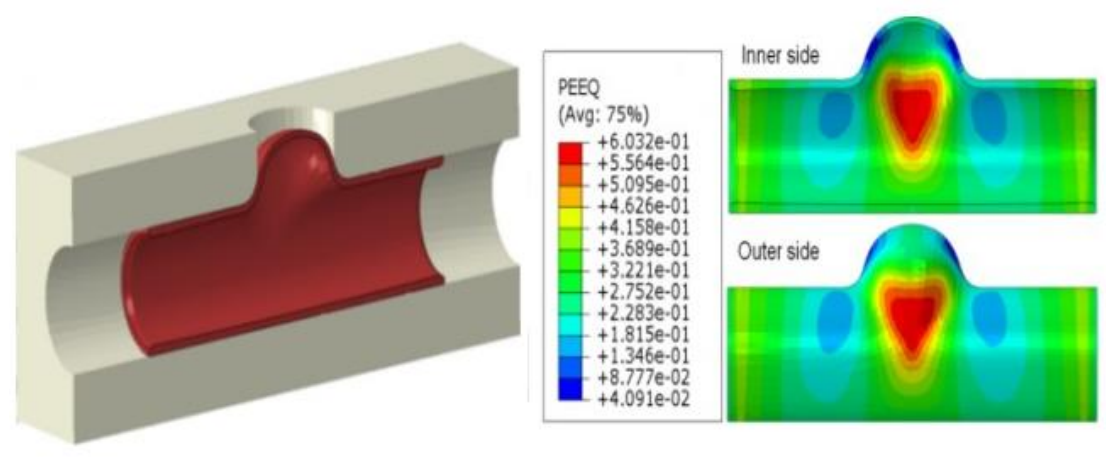

a

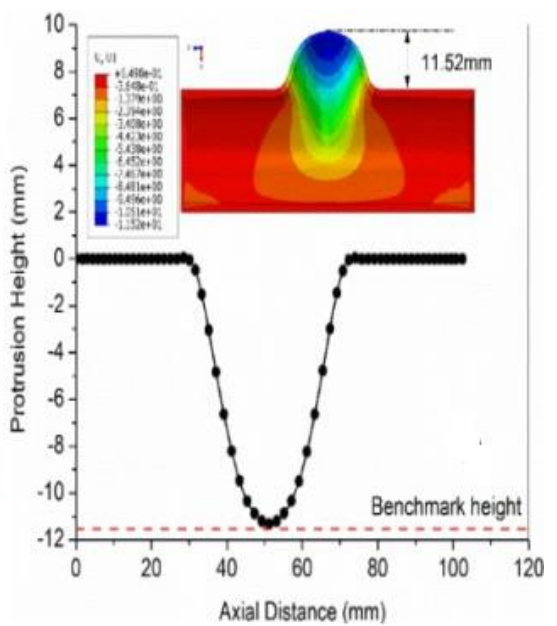

c

Fig. 8 Benchmark results, a; hydro-formed tube, b; protrusion profile, c 
The protrusion profile along the outer surface of tube is measured and plotted in Fig. 8, c, shows that a portion of tube deformed through T-branch and the tube is shortened in the axial feed direction. The protrusion shows a smooth deformed profile that reaches the benchmark line marked on it. The protrusion height of $11.52 \mathrm{~mm}$ from the initial surface is predicted. These results accurately agree with the experimental measurement and LS-dyna numerical analysis as presented in literature and compared in Table 4.

\subsection{Parameter correlations}

\subsubsection{Predicted result}

The accuracy of model predicted results for the responses namely, protrusion height and percentage change in wall thickness is plotted in Fig. 9. It is noticed that the residual square of 0.99 and 0.89 is achieved for the linear fit data of protrusion height and percentage change in wall thickness respectively. It is a clear indicator that the predictions are highly accurate using the developed numerical model for various specified configurations.

Table 4

Result comparison

\begin{tabular}{|l|c|c|c|}
\hline \multirow{2}{*}{$\begin{array}{l}\text { Protrusion height, } \\
\mathrm{mm}\end{array}$} & Present study & Experiment [20] & LS-Dyna simulation [20] \\
\cline { 2 - 4 } & 11.52 & 11.505 & 11.615 \\
\hline
\end{tabular}

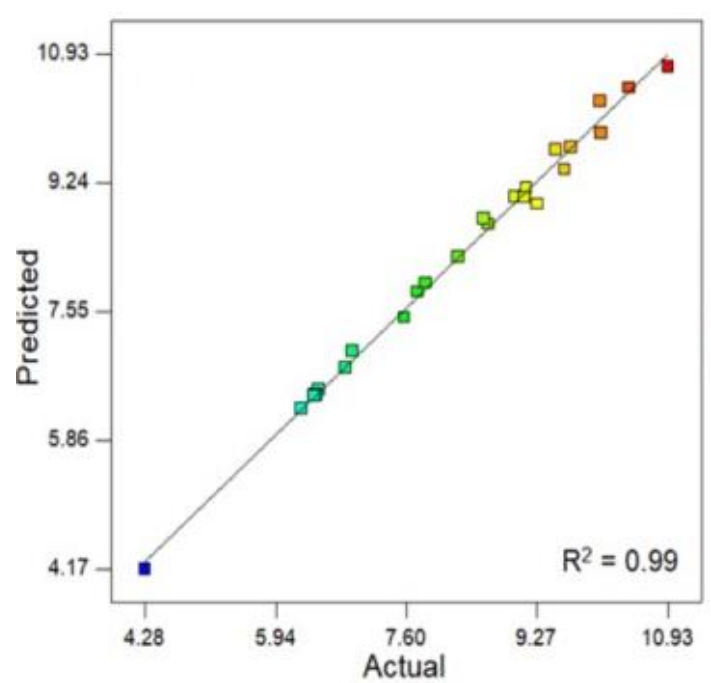

a

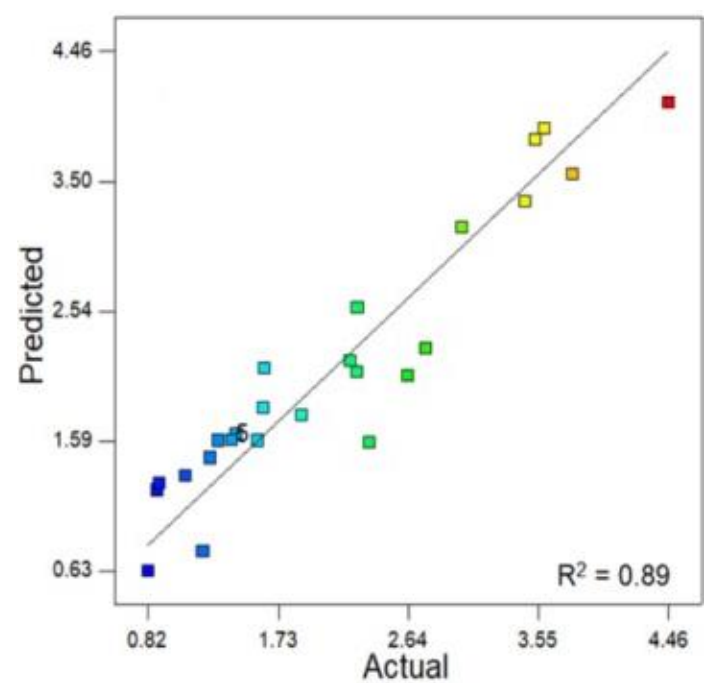

b

Fig. 9 Model predicted data, $\mathrm{a}$ - protrusion height; $\mathrm{b}$ - change in wall thickness

\subsubsection{Main and interactive effects}

The independent and dependent effects of process parameters on the protrusion height and percentage change in wall thickness are discussed. The analyses of variance for both the responses are carried out and the highly influencing process parameters are identified. The probability of responses having less than $5 \%$ of failure rate are considered as significant parameters that influences the present tubular hydro-forming process. Table 5, shows the ANOVA for protrusion height. It is noticed that all the specified parameters have probability of failure less than $5 \%$ that indicates that these parameters are independently influence the tubular hydro-forming process significantly. However, there are certain interactive effects also observed from the second order terms. The interaction of tube wall thickness/coefficient of friction and tube length / coefficient of friction also significantly influences the process. These significantly influencing parameters can be ranked in the following order, i.e., tube length, coefficient of friction, tube wall thickness, BD, $\mathrm{AD}$ and loading time.

The response surface plots of all the specified parameters for protrusion height are presented in Fig. 10. The interaction of $\mathrm{AB}$ indicates that the protrusion height is maximum when these two parameters are kept at its lower bound.
ANOVA for protrusion height

\begin{tabular}{|l|c|c|c|c|c|}
\hline \multicolumn{1}{|c|}{ Source } & $\begin{array}{c}\text { Sum of } \\
\text { Squares }\end{array}$ & $d f$ & $\begin{array}{c}\text { Mean } \\
\text { Square }\end{array}$ & $F$ Value & $\begin{array}{c}p \text {-value } \\
\text { Prob }>F\end{array}$ \\
\hline Model & 64.385 & 14 & 4.598 & 169.216 & $<0.0001$ \\
\hline $\begin{array}{l}\text { A-Tube Wall Thick- } \\
\text { ness }\end{array}$ & 3.033 & 1 & 3.033 & 111.600 & $<0.0001$ \\
\hline B-Tube Length & 30.803 & 1 & 30.803 & 1133.380 & $<0.0001$ \\
\hline C-Loading Time & 0.169 & 1 & 0.169 & 6.252 & 0.0254 \\
\hline $\begin{array}{l}\text { D-Coefficient of } \\
\text { Friction }\end{array}$ & 25.839 & 1 & 25.839 & 950.752 & $<0.0001$ \\
\hline $\mathrm{AB}$ & 0.037 & 1 & 0.037 & 1.384 & 0.2589 \\
\hline $\mathrm{AC}$ & 0.014 & 1 & 0.014 & 0.547 & 0.4715 \\
\hline $\mathrm{AD}$ & 0.623 & 1 & 0.623 & 22.934 & 0.0003 \\
\hline $\mathrm{BC}$ & 0.059 & 1 & 0.059 & 2.182 & 0.1618 \\
\hline $\mathrm{BD}$ & 2.787 & 1 & 2.787 & 102.553 & $<0.0001$ \\
\hline $\mathrm{CD}$ & 0.090 & 1 & 0.090 & 3.322 & 0.0898 \\
\hline $\mathrm{A}^{2}$ & 0.451 & 1 & 0.451 & 16.597 & 0.0011 \\
\hline $\mathrm{B}^{2}$ & 0.019 & 1 & 0.019 & 0.706 & 0.4147 \\
\hline $\mathrm{C}^{2}$ & 0.164 & 1 & 0.164 & 6.065 & 0.0274 \\
\hline $\mathrm{D}^{2}$ & 0.123 & 1 & 0.123 & 4.514 & 0.0519 \\
\hline
\end{tabular}

The response surface plots of all the specified parameters for protrusion height are presented in Fig. 10. The interaction of $\mathrm{AB}$ indicates that the protrusion height is maximum when these two parameters are kept at its lower 
bound.

The protrusion height is significantly increased when the tube length is reduced whereas the change in tube wall thickness has negligible influence on this interaction. The interaction of AD shows similar tendency that the protrusion height is increased when these parameters are kept at its lower bound. In this, coefficient of friction has significant influence that increases the protrusion height significantly than the tube wall thickness.
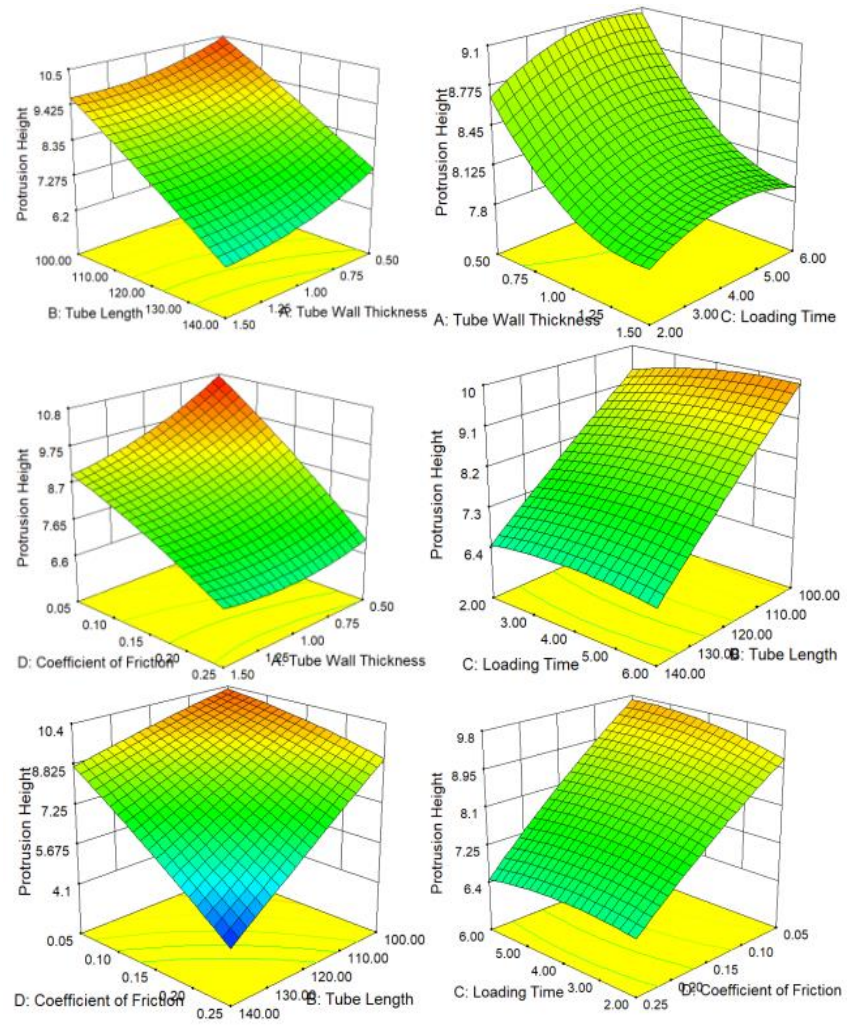

Fig 10 Response surface plot for protrusion height

The interaction of BD indicates different trend in the response that the protrusion height has significant variation when both the tube length and coefficient of friction is altered from maximum to minimum. The interaction of AC shows that the loading time at its mean has significant influence than that of lower and upper bound. But the tube wall thickness has significantly influence the response when it is reduced. The interaction of $\mathrm{BC}$ shows that the loading time is negligible effect whereas the tube length significantly influences the response. The interaction of CD shows that the protrusion height is maximum when the coefficient of friction is low and loading time is high.

It is understood from these response surface plots that the protrusion height can be increased when the tube wall thickness is less. It can easily undergo to plastic deformation thereby improves the protrusion height. Considering the tube length, it is understood that the larger tube length makes higher area of contact with the die. It creates higher friction between these two contact surfaces and reduces the protrusion height when the coefficient of friction is increased in the process. It indicates that it requires proper lubrication to overcome this issue. Also, a slower rate of loading is suggested as the friction between components is higher during process it requires sufficient time for plastic deformation through the die.

The ANOVA for the percentage change in tube wall thickness is given in Table 6 shows that the parameters $\mathrm{A}$ and D has significant influence on the response whereas other parameters are negligible effects on it. Among these two parameters, the tube wall thickness is highly influencing parameter than the coefficient of friction.

The response surface plots for the percentage change in wall thickness are given in Fig. 11. The interaction of $\mathrm{AB}$ and $\mathrm{AD}$ shows that the change of wall thickness is higher when higher thickness tubes are formed using this process whereas the tube length and coefficient of friction have negligible effects on this.
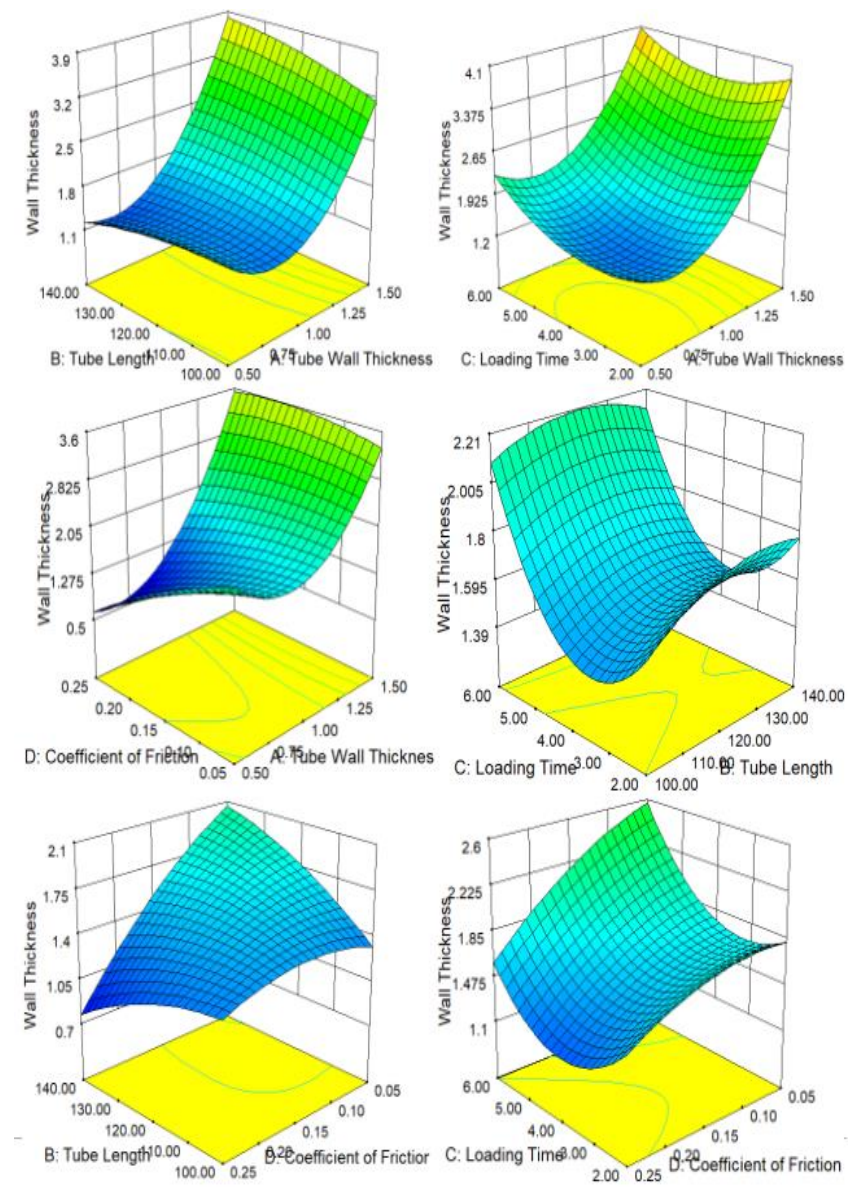

Fig. 11 Response surface plot for change in wall thickness

Table 6

ANOVA for percentage change in wall thickness

\begin{tabular}{|l|c|c|c|c|c|}
\hline \multicolumn{1}{|c|}{ Source } & $\begin{array}{c}\text { Sum of } \\
\text { Squares }\end{array}$ & $d f$ & $\begin{array}{c}\text { Mean } \\
\text { Square }\end{array}$ & $\begin{array}{c}F \\
\text { Value }\end{array}$ & $\begin{array}{c}p \text {-value } \\
\text { Prob }>F\end{array}$ \\
\hline Model & 23.823 & 14 & 1.701 & 8.725 & 0.0001 \\
\hline $\begin{array}{l}\text { A-Tube Wall } \\
\text { Thickness }\end{array}$ & 12.572 & 1 & 12.572 & 64.464 & $<0.0001$ \\
\hline B-Tube Length & 0.040 & 1 & 0.040 & 0.207 & 0.6558 \\
\hline C-Loading Time & 0.556 & 1 & 0.555 & 2.849 & 0.1136 \\
\hline $\begin{array}{l}\text { D-Coefficient of } \\
\text { Friction }\end{array}$ & 1.356 & 1 & 1.356 & 6.957 & 0.0195 \\
\hline AB & 0.279 & 1 & 0.279 & 1.435 & 0.2507 \\
\hline AC & 0.058 & 1 & 0.058 & 0.301 & 0.5913 \\
\hline AD & 0.758 & 1 & 0.758 & 3.886 & 0.0688 \\
\hline BC & 0.007 & 1 & 0.007 & 0.037 & 0.8493 \\
\hline BD & 0.385 & 1 & 0.385 & 1.977 & 0.1815 \\
\hline CD & 0.092 & 1 & 0.092 & 0.471 & 0.5038 \\
\hline A2 & 6.054 & 1 & 6.053 & 31.041 & $<0.0001$ \\
\hline B2 & 0.063 & 1 & 0.062 & 0.322 & 0.5792 \\
\hline C2 & 1.051 & 1 & 1.051 & 5.393 & 0.0358 \\
\hline D2 & 0.108 & 1 & 0.108 & 0.554 & 0.4688 \\
\hline
\end{tabular}


The interaction of $\mathrm{AC}$ shows that the change in wall thickness is higher when higher loading time is provided and the initial tube thickness has same tendency as discussed earlier. The interaction of BC shows that the loading time has significant effect on this response. The change in wall thickness is high when the process is carried out with low rate of loading. The interaction of CD shows that the both these parameters are influencing the process. The change in wall thickness is higher at lower coefficient of friction and slower loading rate.

From these response surface plots, it is understood that the percentage change in wall thickness is higher when the hydro-forming process is carried out at slower loading rate. A sufficient time is required to have severe plastic deformation during process to overcome the higher friction between the component surfaces. Also, the higher initial thickness of tube undergoes severe deformation that leads to higher reduction in tube wall thickness. It indicates that the wall thickness of final component can be controlled by providing proper rate of loading during the process.

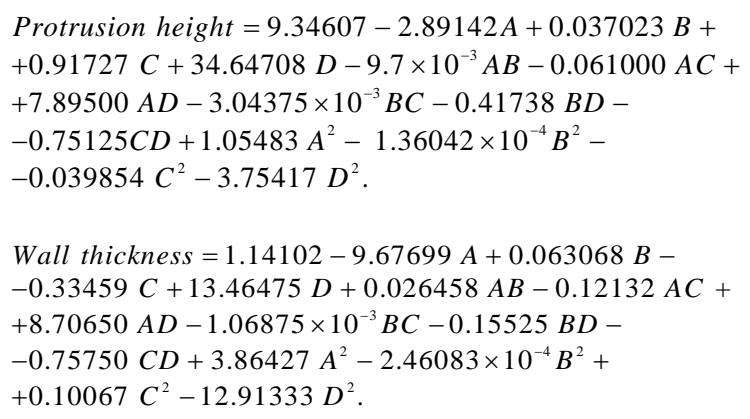

Based on this investigation, the mathematical correlations for protrusion height and percentage change in wall thickness are developed as shown in Eqs. (4) and (5). By substituting input to these equations will yield appropriate responses within the specified range.

\section{Conclusions}

The conclusions based on this investigation is summarized as follows,

- The final protrusion size and change in wall thickness are highly influenced by the specified parameters.

- The higher friction induced during the process attributed to the larger area of contact between component is the major factor that decides the final profiles.

- Proper lubrications should be provided to achieve the required protrusion height with less reduction in wall thickness.

- Also, the forming component requires sufficient time to achieve severe plastic deformation during forming process.

- The slower rate of loading can help to achieve good geometrical tolerances when higher thickness tubes are formed using this process.

\section{References}

1. Alaswad, A.; Benyounis, K.Y.; Olabi, A.G. 2012. Tube hydroforming process: A reference guide, Materials \& Design 33: 328-339.

https://doi.org/10.1016/j.matdes.2011.07.052.
2. Zhan, M.; Guo, X.; Yang, H. 2016. Advances and trends in plastic forming technologies for welded tubes, Chinese Journal of Aeronaut 29: 305-315.

https://doi.org/10.1016/j.cja.2015.10.011.

3. Liu, G.; Peng, J.; Yuan, S.; Teng, B.; Li, K. 2015. Analysis on critical conditions of sidewall wrinkling for hydroforming of thin-walled Tee-joint, International Journal of Machine Tools and Manufacture 97: 42-49. https://doi.org/10.1016/j.ijmachtools.2015.06.004.

4. Lang, L.; Cai, G.; Kiu, K.; Alexandrov, S.; Du, P.; Zheng, H. 2015 Investigation on the effect of through thickness normal stress on forming limit at elevated temperature by using modified MK model, International Journal of Material Formatting, 8: 211-228. https://doi.org/10.1007/s12289-014-1161-3.

5. Cui, X.L.; Wang, X.S.; Yuan, S.J. 2014. Experimental verification of the influence of normal stress on the formability of thin-walled 5A02 aluminum alloy tubes, International Journal of Mechanical Sciences 88: 232243. https://doi.org/10.1016/j.ijmecsci.2014.07.011.

6. Khalfallah, A.; MC.; Oliveira, J.L.; Alves; Zribi, T.; Belhadjsalah, H.; Menezes, H.F. 2015. Mechanical characterization and constitutive parameter identification of anisotropic tubular materials for hydroforming applications, International Journal of Mechanical Sciences 104: 91-103. https://doi.org/10.1016/j.ijmecsci.2015.09.017.

7. Iorio, L.; Maspero, E.; Strano, M. 2014. Hydroforming of locally heat treated tubes, Journal of Manufacturing Processes, 16:157-165.

https://doi.org/10.1016/j.jmapro.2014.01.002.

8. He, Z.; Yuan, S.; Lin, Y.; Wang, X.; Hu, W. 2014. Analytical model for tube hydro-bulging test, part I: Models for stress components and bulging zone profile, International Journal of Mechanical Sciences 87: 297306.

https://doi.org/10.1016/j.ijmecsci.2014.05.009.

9. He, Z.; Yuan, S.; Lin, Y.; Wang, X.; Hu, W. 2014 Analytical model for tube hydro-bulging tests, part II: Linear model for pole thickness and its application, International Journal of Mechanical Sciences 87: 307-315. https://doi.org/10.1016/j.ijmecsci.2014.05.010.

10. Park, J.Y.; Han, S.W.; Jeong, H.S.; Cho, H.R.; Moon, Y.H. 2017 Advanced sealing system to prevent leakage in hydroforming, Journal of Materials Processing Technology 247: 103-110.

https://doi.org/10.1016/j.jmatprotec.2017.04.006.

11. Nakamori, T.; Shukuno, K.; Manabe, K. 2017. Inprocess controlled $\mathrm{Y}$-shape tube hydroforming with high accurate built-in sensors, Procedia Engineering 184: 4349.

https://doi.org/10.1016/j.proeng.2017.04.069.

12. Dong, G. J.; Bi, J.; Du, B.; Chen, X.; Zhao, C. C. 2017. Research on AA6061 tubular components prepared by combined technology of heat treatment and internal high pressure forming, Journal of Material Processing Technology 242: 126-138.

https://doi.org/10.1016/j.jmatprotec.2016.11.035.

13. Yuan, S. J.; Cui, X. L.; Wang, X. S. 2015. Investigation into wrinkling behavior of thin-walled 5A02 aluminum alloy tubes under internal and external pressure, International Journal of Mechanical Sciences 92: 245-258. https://doi.org/10.1016/j.ijmecsci.2014.12.017. 
14. Guo, X.; Ma, F.; Guo, Q.; Luo, X.; Kim, N.; Jin, K. 2017. A calculating method of tube constants of ductile fracture criteria in tube free bulging process based on M$\mathrm{K}$ theory, International Journal of Mechanical Sciences 140(6): 128-129. https://doi.org/10.1016/j.ijmecsci.2017.04.012.

15. Khodko, O.; Zaytsev, V.; Sukaylo, V.; Verezub, N.; Scicluna, S. 2015. Experimental and numerical investigation of processes that occur during high velocity hydroforming technologies: An example of tubular blank free bulging during hydrodynamic forming, Journal of Manufacturing Processes 20: 304-313. https://doi.org/10.1016/j.jmapro.2015.06.016.

16. Hashemi, S. J.; Moslemi Naeini, H.; Liaghat, G. H.; Azizi Tafti. R.; 2015. Prediction of bulge height in warm hydroforming of aluminum tubes using ductile fracture criteria, Archives of Civil and Mechanical Engineering 15: 19-29. https://doi.org/10.1016/j.acme.2014.08.003.

17. Cui, X. L.; Wang, X.; Yuan, S. J. 2014. Deformation analysis of double-sided tube hydroforming in squaresection die, Journal of Material Processing Technology 214: $1341-51$. https://doi.org/10.1016/j.jmatprotec.2014.02.005.

18. Zribi, T.; Khalfallah, A.; BelHadjSalah, H. 2013. Experimental characterization and inverse constitutive parameters identification of tubular materials for tube hydroforming process, Materials \& Design 49: 866-877. https://doi.org/10.1016/j.matdes.2013.02.077.

19. Bihamta, R.; D'Amours, G.; Bui, Q. H.; Guillot, M.; Rahem, A.; Fafard, M. 2013. Numerical and experimental studies on the new design concept of hydroforming dies for complex tubes, Materials \& Design 47: 766778. https://doi.org/10.1016/j.matdes.2012.12.075.

20. Alaswad, A.; Benyounis, K. Y.; Olabi, A. G. 2011. Finite element comparison of single and bi-layered tube hydroforming processes, Simulation Modelling Practice and Theory 19: 1584-1593 https://doi.org/10.1016/j.simpat.2011.03.007.

21. Zhang, L.; Liu, H.; Wang, W. 2017. Numerical simulation and analysis of hydromechanical deep drawing process for half-three-way tube, Procedia Engineering 174: 524-529. https://doi.org/10.1016/j.proeng.2017.01.181.

22. Nikhare, C.; Weiss, M.; Hodgson, P. D. 2017. Buckling in low pressure tube hydroforming, Journal of Manufacturing Processes 28: 1-10. https://doi.org/10.1016/j.jmapro.2017.05.015.

23. Palumbo, G.; Piccininni, A.; Guglielmi, P.; Di Michele, G. 2015. Warm hydro forming of the heat treatable aluminium alloy AC170PX, Journal of Manufacturing Processes 20: 24-32. https://doi.org/10.1016/j.jmapro.2015.09.012.

24. Jain, S.; Rai, D.C.; Sahoo, D.R. 2008. Postyield cyclic buckling criteria for aluminum shear panels, Journal of Applied Mechanics 75: 021015. https://doi.org/10.doi:10.1115/1.2793135.

\section{J. Saji Soundara Raj, T. Christopher, K. Kalaichelvan}

\section{PROCESS PARAMETER CORRELATION IN LOW PRESSURE HYDRO FORMING OF 6063-O ALUMINIUM TUBES}

S u m m a r y

The study is performed to investigate the effects of low pressure tubular hydro-forming process parameters on the protrusion height and percentage change in wall thickness of 6063-O aluminium tubes. A mathematical correlation for these parameters are developed employing BoxBehnken response surface method. The required responses are obtained using a developed finite element model considering elastic-plastic material behaviour and validated. It is inferred that the higher friction induced on the contact surfaces of the components significantly influences the geometrical dimensions of final product. Also, it is suggested that the components require sufficient time period to undergo severe plastic deformation that can be provided by slower rate of loading during process.

Keywords: hydro-forming, FEA, RSM, elastic-plastic, 6063, aluminium.

Received March 09, 2018 Accepted February 15, 2019 